\title{
New As-S Cage Structures with Organometallic Components Formed by Complex-Induced Realgar Fragmentation**
}

By Henri Brunner, Bernhard Nuber, Ludwig Poll, and Joachim Wachter*

\section{Dedicated to Professor Ernst Otto Fischer on the occasion of his 75 th birthday}

Substituent-free ligands from the elements of groups 15 and 16 are interesting primarily because of their vast structural diversity. ${ }^{[1,2]}$ Similarities exist above all in the formation of multinuclear complexes. However, the ability of $\mathrm{P}$ and As ligands to form ring systems is unusual; these ring systems show remarkable parallels to cyclic hydrocarbon ligands through the isolobal relationship $\mathrm{P}(\mathrm{As}) \longleftrightarrow \mathrm{CH}$. Relatively little is known to date about complexes with ligands that contain elements from groups 15 and 16 . A simple route to such compounds is the fragmentation of $\mathrm{As}_{4} \mathrm{~S}_{4}$ with reactive transition metal complexes. Mixed realgar fragmentation products that have so far been structurally characterized are complexes with cyclo- $\mathrm{As}_{2} \mathrm{~S}^{[1 \mathrm{c}]} \mathrm{As}_{2} \mathrm{~S}_{3},{ }^{[3]}$ and $\mathrm{As}_{3} \mathrm{~S}_{3}$ ligands. ${ }^{[4]}$ The $\mathrm{AsS}_{3}$ building block, ${ }^{[5]}$ the first molecular example from the extensive class of sulfo salt minerals, is of particular significance. ${ }^{[6]}$ Since the investigations were carried out on complexes with different structures and with various metal centers, nothing is known as yet about the fragmentation mechanism of realgar. ${ }^{[3,7]}$ We report here on the synthesis and structure determination of bi- and trinuclear $\mathrm{Cp}^{\times} \mathrm{Co}$ complexes $\left(\mathrm{Cp}^{\times}=\eta^{5}-\mathrm{C}_{5} \mathrm{Me}_{4} \mathrm{Et}\right)$ with $\mathrm{AsS}$ and $\mathrm{As}_{2} \mathrm{~S}_{3}$ ligands in new modes of coordination and their reactivity relationships with one another.

The reaction of 1 with stoichiometric quantities of $\mathrm{As}_{4} \mathrm{~S}_{4}$ (toluene, $80^{\circ} \mathrm{C}$ ) affords complexes $2-5$ in yields between 6 and $13 \%$. All compounds were characterized analytically ${ }^{[8]}$ and conclusions about the symmetry can be drawn from the ${ }^{1}$ H NMR spectra (Table 1). X-ray structure determinations were carried out for $\mathbf{2}$ and $\mathbf{5}$. Since the properties of $\mathbf{3}$ are very

$\left[\left\{\mathrm{Cp}{ }^{\mathrm{x}} \mathrm{Co}(\mathrm{CO})\right\}_{2}\right] \quad 1$

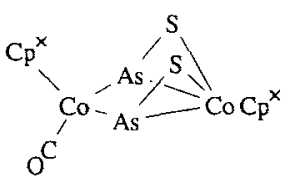

2

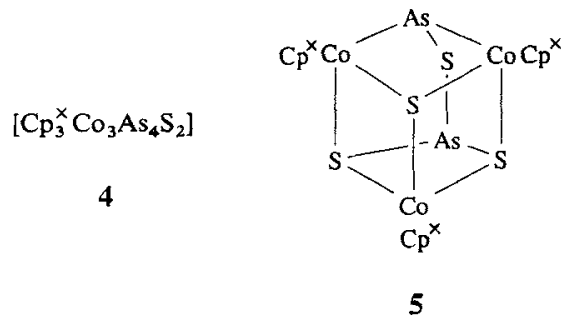

[*] Dr. J. Wachter, Prof. Dr. H. Brunner, L. Poll Institut für Anorganische Chemie der Universität D-93040 Regensburg (FRG)

Telefax: Int. code + (941)943-4439

Dr. B. Nuber

Anorganisch-chemisches Institut der Universität Heidelberg D-69120 Heidelberg (FRG)

[**] We thank Prof. Dr. G. Huttner, Heidelberg, for providing the facilities for the structure determination.
Table 1. ${ }^{1}$ H NMR spectroscopic data [a] of compounds $2-5$

\begin{tabular}{llll}
\hline & $\delta\left(\mathrm{CH}_{2} \mathrm{CH}_{3}\right)[\mathrm{b}]$ & $\delta\left(\mathrm{CH}_{3}\right)$ & $\delta\left(\mathrm{CH}_{2} \mathrm{CH}_{3}\right)[\mathrm{b}]$ \\
\hline 2 & $0.93(\mathrm{t}, 3 \mathrm{H})$, & $1.64(\mathrm{~s}, 6 \mathrm{H}), 1.71(\mathrm{~s}, 6 \mathrm{H})$, & $2.26(\mathrm{q}, 2 \mathrm{H})$, \\
& $1.11(\mathrm{t}, 3 \mathrm{H})$ & $1.92(\mathrm{~s}, 6 \mathrm{H}), 1.93(\mathrm{~s}, 6 \mathrm{H})$ & $2.36(\mathrm{q}, 2 \mathrm{H})$ \\
$\mathbf{3}$ & $0.95(\mathrm{t}, 6 \mathrm{H})$ & $1.65(\mathrm{~s}, 6 \mathrm{H}), 1.66(\mathrm{~s}, 6 \mathrm{H})$, & $2.27(\mathrm{q}, 2 \mathrm{H})$, \\
& & $1.75(\mathrm{~s}, 6 \mathrm{H}), 1,76(\mathrm{~s}, 6 \mathrm{H})$ & $2.28(\mathrm{q}, 2 \mathrm{H})$ \\
$\mathbf{4}$ & $0.92(\mathrm{~m}, 6 \mathrm{H})$, & $1.49(\mathrm{~s}, 3 \mathrm{H}), 1.50(\mathrm{~s}, 3 \mathrm{H})$, & $2.12(\mathrm{~m}, 4 \mathrm{H})$, \\
& $1.11(\mathrm{t}, 3 \mathrm{H})$ & $1.51(\mathrm{~s}, 3 \mathrm{H}), 1.54(\mathrm{~s}, 3 \mathrm{H})$, & $2.39(\mathrm{q}, 2 \mathrm{H})$ \\
& $1.55(\mathrm{~s}, 3 \mathrm{H}), 1.56(\mathrm{~s}, 3 \mathrm{H})$, \\
& $1.60(\mathrm{~s}, 3 \mathrm{H}), 1.61(\mathrm{~s}, 3 \mathrm{H})$, \\
& $1.85(\mathrm{~s}, 3 \mathrm{H}), 1.86(\mathrm{~s}, 3 \mathrm{H})$, \\
5 & $1.88(\mathrm{~s}, 6 \mathrm{H})$ \\
& & $1.47(\mathrm{~s}, 6 \mathrm{H}), 1.49(\mathrm{~s}, 6 \mathrm{H})$, \\
& & $1.52(\mathrm{~s}, 6 \mathrm{H}), 1.57(\mathrm{~s}, 12 \mathrm{H})$, & $2.10(\mathrm{~m}, 6 \mathrm{H})$ \\
& & $1.60(\mathrm{~s}, 6 \mathrm{H})$ \\
\hline
\end{tabular}

[a] $250 \mathrm{MHz}, \mathrm{CDCl}_{3}$, TMS int.; [b] ${ }^{3} \mathrm{~J}(\mathrm{H}, \mathrm{H})=7.6 \mathrm{~Hz}$.

similar to those of the structurally characterized complex 6 $\left(\mathrm{Cp}^{*}=\mathrm{C}_{5} \mathrm{Me}_{5}\right),{ }^{[3]}$ this suggests that also in 3 a chain, in which $\mathrm{S}$ and As atoms alternate, bridges the two Co centers. In contrast, the structure of $\mathbf{4}$ remains open because of the numerous possible isomers.

$\left[\mathrm{Cp}_{2}^{*} \mathrm{Co}_{2} \mathrm{As}_{2} \mathrm{~S}_{3}\right] \quad 6$

The most important feature of the crystal structure of $2^{[9]}$ is the two Co centers syn bridged by two $\eta^{1}: \eta^{2}$-AsS ligands (Fig. 1). A terminal $\mathrm{CO}$ group at $\mathrm{Co} 2$, also evident by an IR

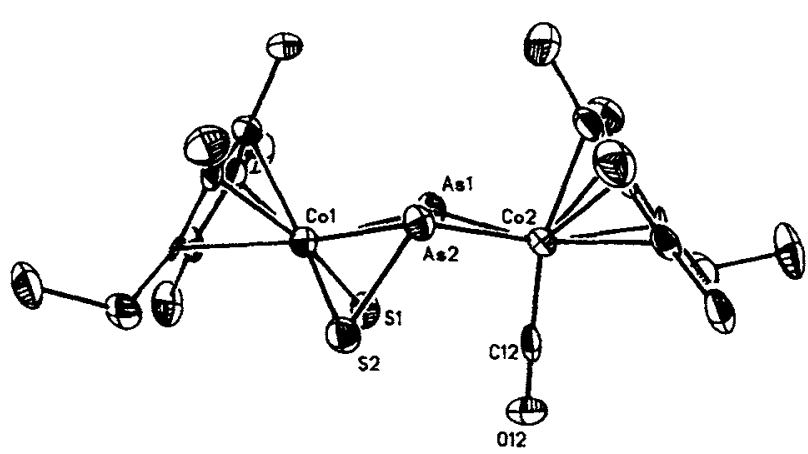

Fig. 1. Crystal structure of 2. Selected distances $\left[\AA \AA\right.$ and angles $\left[{ }^{\circ}\right]$ : Col-As 1 2.473(2), Co1-As2 2.465(2), Co1-S1 2.275(4), Co1-S2 2.279(4), Co2-As1 2.383(3), Co2-As2 2.381(3), As1-S1 2.174(4), As2-S2 2.164(4), As1 $\cdots$ As2 2.717(2), S1‥S2 3.278(4); As1-Co1-As2 66.7(1). As1-Co1-S1 54.3(1), As1Co1-S2 102.3(1), S1-Co1-S2 92.1(2), As1-Co2-As2 69.5(1), As1-Co2-C12 93.3(4), As2-Co2-C12 97.3(4), Co1-As1-Co2 107.7(1), Co1-As1-S1 58.2(1), Co2-As1-S1 110.7(1).

absorption at $1987 \mathrm{~cm}^{-1}$, is responsible for the formal saturation of the two Co centers. The two As atoms come remarkably close to each other $(2.717(2) \AA),{ }^{[10]}$ whereas the $\mathrm{S}-\mathrm{S}$ distance $(3.278 \AA)$ is greater than that for bonding interactions. The $\mathrm{Co}-\mathrm{S}$ distances in the frameworks of $\mathbf{6}$ and 2 are the same length; of the two different $\mathrm{Co}-$ As distances $(A=0.08 \AA)$ in 2 , however, even the shorter ones are about $0.06 \AA$ longer than those in 6 . The As-S distance (mean $2.169 \AA$ ) is about $0.07 \AA$ shorter than that in the minerals $\mathrm{As}_{2} \mathrm{~S}_{3}$ and $\mathrm{As}_{4} \mathrm{~S}_{4}{ }^{[11]}$ and other complexes which contain the $\eta^{2}: \eta^{2}$ AsS ligand. ${ }^{[7,12]}$

The crystal structure of $\mathbf{5}^{[13]}$ is characterized by a $\mathrm{Co}_{3} \mathrm{As}_{2} \mathrm{~S}_{4}$ cage, in which one $\mu_{3}-\mathrm{S}$ and one $\mu_{3}-\mathrm{As}_{2} \mathrm{~S}_{3}$ ligand form the main constituents of a distorted cube (with As 1 above a plane) (Fig. 2). The construction of the $\mathrm{As}_{2} \mathrm{~S}_{3}$ bridge can be seen as a molecular section from the $\mathrm{As}_{n} \mathrm{~S}_{2 n+1}$ chain 


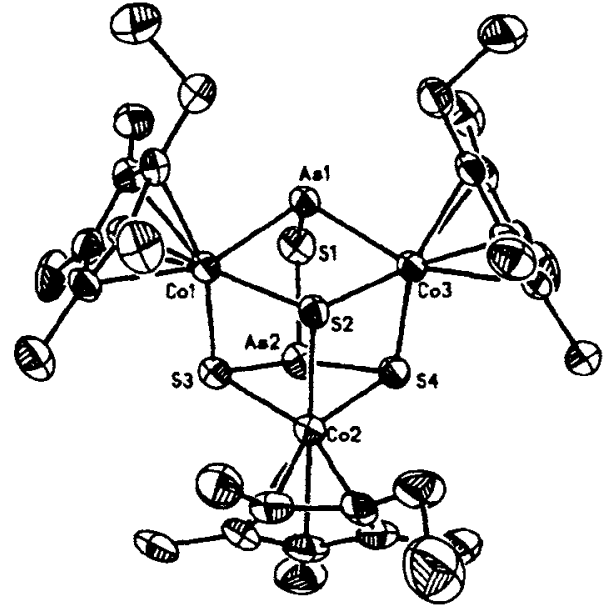

Fig. 2. Crystal structure of 5. Selected distances $[\AA]$ and angles [ ]: Co1-As 1 2.342(3), Co1-S2 2.266(4), Co1-S3 2.209(4), Co2-\$2 2.274(4), Co2-S3 2.272(4). Co2-S4 2.274(4), Co3-As1 2.341(3), Co3-S2 2.263(4). As1-S1 2.318(4). As2-S1 2.196(1), As2-S3 2.29?(4), As2-\$4 2.292(4); As1-Co1-S2 78.5(1), Co1-As1-Co3 98.1(1), Col-S2-Co3 102.7(1), S3-Co2-S4 89.0(1). S3-As2-S4 88.1(1), AsI-S1As2 98.0(1).

with trigonal pyramidal $\mathrm{AsS}_{3}$ subunit ${ }^{[6]}$ typical for sulfo salts; at the As 1 atom two Co atoms replace two S atoms. Correspondingly, the As-S distances also vary between 2.195 and $2.318 \AA$. Of the noble gas-configurated Co centers, $\mathrm{Co} 1$ and $\mathrm{Co} 3$ are symmetry equivalent, which is also in accordance with the ${ }^{1} \mathrm{H}$ NMR spectrum (Table 1).

Since the reaction of 1 with $\mathrm{As}_{4} \mathrm{~S}_{4}$ in boiling xylene (15h) only affords 3 and 5 in 11 and $51 \%$ yield, respectively, it appears likely that 2 and 4 are intermediate products. Indeed, warming solutions of 2 to $110^{\circ} \mathrm{C}$ affords $3(25 \%$ yield $)$, $\mathbf{4}(10 \%)$, and $\mathbf{5}(18-28 \%)$. Interestingly, the addition of sulfur does not cause the linkage of the two AsS ligands, rather, only the isolation of a small quantity of $\left[\mathrm{Cp}_{2}^{\mathrm{x}} \mathrm{Co}_{2} \mathrm{~S}_{4}\right]^{[15]}$

It can be concluded that AsS units play an important role in the construction of new cage structures which are characterized by the $\mathrm{As}_{2} \mathrm{~S}_{3}$ framework. A comparison with the fragmentation of the $\mathrm{As}_{4}$ tetrahedron by 1 seems appropriate ${ }^{[16]}$ although the apparently rapid opening of the edges of the $\mathrm{As}_{4} \mathrm{~S}_{4}$ framework has not been proven to date. Compound $\mathbf{2}$ is, however, structurally analogous to $[\mathrm{Cp} * \mathrm{Co}-$ $\left.\left(\mu-\eta^{4}: \eta^{1}: \eta^{1}-\mathrm{As}_{4}\right) \mathrm{Co}(\mathrm{CO}) \mathrm{Cp}^{*}\right]$, an intermediate from this reaction, when the two S-"wing tips" are replaced by an As-As building block. Also this complex is thermally unstable. However, it rearranges into a $\mathrm{Co}_{3} \mathrm{As}_{6}$ framework, which can be described as a strongly distorted $\mathrm{As}_{6}$ prismane constructed from three $\mathrm{As}_{2}$ units.

\section{Experimental Procedure}

The suspension from 1 (902 $\mathrm{mg}, 1.91 \mathrm{mmol})$ and $\mathrm{As}_{4} \mathrm{~S}_{4}(817 \mathrm{mg}, 1.91 \mathrm{mmol})$ in toluene $(50 \mathrm{~mL})$ was stirred for $15 \mathrm{~h}$ at $80 \% \mathrm{C}$. After the solvent had been removed, the oily brown residue was taken up in toluene and prepurified on $\mathrm{SiO}_{2}$ (column $10 \times 3 \mathrm{~cm}$ ). With toluene ether $10: 1$ first a very broad red-brown zone was eluted and then a brown zone which contained 2 in $10 \%$ yieid. The first zone was then chromatographed on $\mathrm{SiO}_{2}$ (column $84 \times 2.5 \mathrm{~cm}$ ). With toluene/ pentane $1: 1$ a series of compounds was eluted: orange-red $\left[\mathrm{Cp}^{x} \mathrm{Co}(\mathrm{CO})_{2}\right]$, green-brown 4, red-brown 5 , and finally violet 3 (yields: $13(4) .11(5), 6(3) \%$ ). Recrystallization at $-20: \mathrm{C}$ from toluene pentane mixtures afforded brown (2.4.5) and dark violet (3) crystals, respectively.

Received: May 18, 1993 [Z6089 IE] German version: Angew. Chem. 1993, 105, 1699

[1] The most current review articles: O. J. Scherer, Angew. Chem. 1990, 102, 1137: Angew: Chem. Int. Ed. Engl. 1990. 29.1104; b) A.-J. DiMaio. A. L. Rheingold, Chem. Rev. 1990, 90, 169: c) M. Di Vaira, P. Stoppioni, Coord. Chem. Re'. 1992, 120, 259
[2] J. Wachter, Angew: Chem. 1989, 101, 1645; Angew. Chem. Int. Ed. Engl. 1989. 28,1613

[3] H. Brunner, H. Kauermann, B. Nuber, J. Wachter, M. L. Ziegler, Angew. Chem. 1986. 98, 551: Angett. Chem. Inl. Ed. Engl. 1986, 25, 557.

[4] M. Di Vaira, P. Stoppioni, M. Peruzzini, Inorg. Chim Acta 1987, 132, 37.

[5] G. A. Zank, T. B. Rauchfuss, S. R. Wilson, J. Am. Chem. Soc. 1984, 106, 7621

[6] For the obtained rings, chains, and networks from anionic. pyramidal $X E_{3}$ subunits ( $\mathrm{X}=\mathrm{As}$. Sb, Bi; $\mathrm{E}=\mathrm{S}, \mathrm{Se}$, Te) see: W. Nowacki, Schweiz, Mineral. Petrogr. Mitt. 1969. 49, 109; E. Hellner, J. Geol. 1958, 66, 503: Y. Takeuchi, R. Sadanaga, Z. Kristallogr. 1969, $530,346$.

[7] The 48 e cluster $\left[\mathrm{Cp}_{2}^{*} \mathrm{Mo}_{2} \mathrm{AsS}_{3} \mathrm{Co}(\mathrm{CO})_{2}\right]$ contains a $\mu_{2} \cdot \eta^{2}$-AsS ligand, however this ligand is derived from the compound $\left[\mathrm{Cp}_{2}^{*} \mathrm{Mo}_{2} \mathrm{As}_{2} \mathrm{~S}_{3}\right]$, which has not yet been confirmed structurally ( $\mathrm{H}$. Brunner, $\mathrm{H}$. Kauermann, U. Klement, J. Wachter. T. Zahn, M. L. Ziegler, Angew: Chem. 1985, 97, 122; Angew. Chem. Int. Ed. Engl. 1985, 24,132).

[8] Correct C. H. S elemental analyses. FD mass spectra (toluene) $2: m / z 658.2$ $\left(\mathrm{M}^{\oplus}\right) ; 3: m^{\prime}=662.3\left(\mathrm{M}^{\oplus}\right) ; 4: m /=988.7\left(\mathrm{M}^{\oplus}\right) ; 5: m_{i}=902.5\left(\mathrm{M}^{\oplus}\right)$.

[9] Compound 2 crystallizes in the form of brown plates, which contain half a molecule of toluene (disordered) per formula unit. Space group $C 2 h / 5, P 2_{1}$ in (no. 14), $a=9.046(4), b=26.01(1), c=12.636(5) \AA, \beta=$ $99.59(3), V=2931.5 \AA^{3}(25$ reflections $(3.0<2 \theta<19.0)): Z=4$. SyntexR.3 diffractometer $\left(\mathrm{Mo}_{K_{x}}\right), 3.0<2 \theta<52.5^{\circ} ; 6069$ reflections, of which 2537 with $\mathrm{I}>2.5 \sigma(I)$ were used for the refinement. Decrease in intensity of the reference reflections during the measurement balanced up to $55 \%$ by corresponding correction of the intensities. Patterson and Fourier methods. anisotropic refinement to $R=0.073, R_{w}=0.055$ [14].

[10] As. As bonds in transition metal complexes lie in the range 2.273(3) $2.445(4) \AA[1$ a]. However. distances of 2.57 and $2.76 \AA$ have also previously been discussed as being of bonding nature (A. L. Rheingold, M. J. Foley. P. J. Sullivan. J. Am. Chem. Soc. 1982. 104, 4727).

[11] D. J. E. Mullen. W. Nowacki, Z. Kristallogr. Krisiallgeom. Kristallphys. Kristallchem. 1972, 136, 48, and references therein.

[12] A.-J. DiMaio. A. L. Rheingold, Inorg. Chem. 1990, 29, 798.

[13] 5 crystallizes in the form of thin, long plates of the dimensions $0.05 \times 0.15 \times 0.7 \mathrm{~mm}^{3}$. Space group $C 2 h / 5, P 2$ in (no. 14), $a=8.849(3)$, $b=21.81(2), c=19.54(2) \AA, \beta=96.24(6), V=3748.8 \AA^{3}$ (16 reflections $\left.\left(4.3<2 \theta<14.8^{\circ}\right)\right), Z=4$. Syntex-R3 diffractometer $\left(\mathrm{Mo}_{\mathrm{kn}}\right), 3.0<2 \theta<$ $47.5 ; 5878$ reflections, of which 2867 with $I<2.5 \sigma(I)$ were used for the refinement. Empirical absorption correction. Patterson and Fourier methods, anisotropic refinement to $R=0.060 . R_{\mathrm{w}}=0.048$ [14]

[14] Further details of the crystal structure investigation may be obtained from the Fachinformationszentrum Karlsruhe, Gesellschaft für wissenschaftlich-technische Information $\mathrm{mbH}, \mathrm{D}-76344$ Eggenstein-Leopoldshafen (FRG) on quoting the depository number CSD-57465, the names of the authors, and the journal citation.

[15] H. Brunner, N. Janietz. W. Meier, G. Sergeson. J. Wachter, T. Zahn, M. L. Ziegler, Angew. Clem. 1985. 97, 1056; Angew. Chem. Int. Ed. Engl. 1985. 24. 1060 .

[16] O. J. Scherer, K. Pfeiffer. G. Wolmerhäuser, Chem. Ber. 1992, 125, 2367.

\section{The First Heteroallyl Metal Complexes of Arsenic with the Coordination Number $2^{* *}$}

By Uwe Wirringa, Herbert W. Roesky, * Mathias Noltemeyer, and Hans-Georg Schmidt

\section{Dedicated to Professor Helmut Werner} on the occasion of his $60 \mathrm{th}$ birthday

The chemistry of low-coordinate group 15 elements of the periodic table has already been the subject of numerous investigations. Particular emphasis was focused on phosphorus compounds such as phosphaalkynes and -alkenes, ${ }^{[1]}$ diphosphenes, ${ }^{[2]}$ and iminophosphanes. ${ }^{[3]}$ These compounds have already been used as synthetic building blocks. ${ }^{[1-4]}$ In contrast, the chemistry of compounds containing low-coor-

[*I Prof. Dr. H. W. Roesky, Dipl.-Chem. U. Wirringa, Dr. M. Noltemeyer. H.-G. Schmidt

Institut für Anorganische Chemie der Universität

Tammannstrasse 4, D-37077 Göttingen

Telefax: Int code $+(551) 393373$

$\left[{ }^{* *}\right]$ This work was supported by the Deutsche Forschungsgemeinschaft and the Fonds der Chemischen Industrie. 